\title{
La recherche de soi dans la littérature postcoloniale. Entre Orient et Occident dans Nulle part dans la maison de mon père d'Assia Djebar
}

oui, ce corps porté soudain de plus en plus vivement en cercles se déroulant multipliés à la fois dans l'espoir et la retenue muette

corps sans ancrage

(Djebar 1999, 12)

Résumé: L'objectif du présent article est de montrer comment l'identité (post)coloniale de la narratrice du dernier livre, autobiographique, d'Assia Djebar, Nulle part dans la maison de mon père, s'inscrit dans le concept de rhizome élaboré par Deleuze et Guattari. La langue et la culture du colonisateur influencent le colonisé, qui n'oublie cependant pas sa propre tradition, aboutissant ainsi à la création d'une identité rhizomorphe complexe.

L’article est divisé en trois parties. La première analyse les relations entre le français et l'arabe. La deuxième se penche sur la culture, tandis que la dernière est consacrée à la tradition. L'opposition entre l'Occident et l'Orient, loin d'être dichotomique, se révèle bien plus complexe, les deux héritages continuant à se confondre. Pour survivre dans cette réalité aux multiples facettes, la narratrice devrait accepter les rhizomes dans lesquels elle vit (et qui vivent en son for intérieur).

Mots clés: Assia Djebar, littérature postcoloniale, identité, rhizome, langue, culture, colonialisme

Publié en 2007, Nulle part dans la maison de mon père est le dernier roman d'Assia Djebar, le plus autobiographique (cf. Mortimer 2013, 111-129). Écrit douze ans après la mort de son père, le livre raconte l'enfance et l'adolescence algériennes de la narratrice, facilement identifiable à l'auteur qui joue habilement sur l'ambivalence de la notion de père et celle de maison, se référant à la fois à sa situation particulière, à l'héritage islamique et, ce qui nous intéresse le plus dans le présent travail, à la situation coloniale et ses conséquences.

$\mathrm{Au}$ début de son livre, dans une partie intitulée « Intermède », Djebar (2007, 35) affirme : 
[L]a colonie, c'est d'abord un monde divisé en deux [...].

La colonie est un monde sans héritiers, sans héritage.

Les enfants des deux bords ne vivront pas dans la maison de leurs pères ! Et s'ils ont tous des ancêtres, ceux-ci ne leur auront laissé que la rancune en partage, au mieux l'oubli, le plus souvent le désir de partir, de fuir, de renier, de chercher n'importe quel horizon pour, dans les draps de crépuscule, s'enfouir...

L'écrivaine dépeint ici le destin tragique des générations en quête de soi, de leur place dans l'univers et de leur héritage. Le but de la littérature postcoloniale est d'assumer sa propre culture et sa propre histoire, de les récupérer et d'en prendre le contrôle (Green 1993, 958). L'écriture djebarienne vise d'habitude à reconstruire la dignité de la nation algérienne et sa fierté, à la guérir et à la consoler ${ }^{1}$ (Sokołowicz 2017b, 47-48). Le dernier roman de l'écrivaine est pourtant différent. Concentré sur la narratrice et ses émotions, il semble entièrement marqué par la mort : « J'en reviens à ce moi d'autrefois, dissipé, qui ressuscite dans ma mémoire et qui, s'ouvrant au vent de l'écriture, incite à se dénoncer soi-même, à défaut de se renier, ou d'oublier ! Se dire à soi-même adieu » (Djebar 2007, 404).

Djebar savait que Nulle part dans la maison de mon père serait son dernier livre, livre d'adieu dont il lui était bien difficile de parler (cf. Provitola 2015, 73). Nous voudrions le présenter ici en tant que l'exemple de cette recherche douloureuse de soi qui devient l'expérience de tous ceux qui ont grandi dans la réalité coloniale et ont essayé de retrouver leur place une fois la liberté du pays regagnée. Djebar $(2007,404)$ parle de la « société coloniale bifide ». Cette société est pourtant beaucoup plus complexe, même si la métaphore biologique ne semble pas tout à fait impropre. "Les identités ne sont jamais unifiées »², écrit Hall (2003, 4), mais fragmentées et fracturées. Les identités postcoloniales s'inscrivent bien dans la notion de rhizome. Le concept de Deleuze et Guattari (1979, 45-46), selon lequel " [ê]tre rhizomorphe, c'est produire des tiges et filaments qui ont l'air de racines, ou mieux encore se connectent avec elles en pénétrant dans le tronc, quitte à les faire servir à de nouveaux usages étranges », répond bien à la spécificité des études postcoloniales. Caractérisé par le « mouvement », la « rupture » et l'« évasion » (Fulford 2002, 28), le rhizome rend parfaitement la réalité coloniale se forgeant dans l'enchevêtrement de langues, cultures et traditions. Dans Nulle part dans la maison de mon père, c'est entre Orient et Occident que se construit l'identité rhizomatique de la narratrice.

1 Assia Djebar est un nom d'écriture de Fatima Zohra Imalayène, choisi en 1956. Le mot « "djebar”, en arabe dialectal, signifie "guérisseur”, et “assia”, “celle qui console, qui accompagne de sa présence” " (Selao 2004, 150).

2 Toutes les traductions ont été réalisées par l'auteure de l'article. 


\section{La langue ou « les deux visages d'une même poésie ॥}

Contrairement à ceux selon qui il est nécessaire d'écrire dans sa langue nationale pour se réconcilier avec l'histoire coloniale et passer à l'acte de la libération absolue (cf. Tageldin 2009, 467-468), Djebar écrit en français, « lieu de creusement de [s]on travail, espace de [s]a méditation et de [s]a rêverie » (Djebar 2010, 414). Dans L'Amour, la fantasia, elle compare le français à la tunique de Nessus qui l'a enveloppée dès l'enfance, en provocant des souffrance terribles (Djebar 2014 [1985], 302). Selon Connell (2013, 292), la tunique, bien que toxique, est aussi salutaire. En effet, dans Nulle part dans la maison de mon père, le français n'est pas la langue du colonisateur-agresseur, mais surtout la langue du père auquel la narratrice cherche à s'identifier (cf. Provitola 2015, 84) :

[La] langue, celle des « Autres », [...] reste son armure, même si, après l'étude, il lui arrive d'aller chez l'épicier kabyle et là, quelques fois - le jeudi peut-être -, de faire sa partie de domino, de se remettre aussi à parler en arabe, un arabe avec les « $\mathrm{r}$ » non roulés, parfois avec un début de bégaiement qu’il maîtrise vite. (Djebar 2007, 85)

Selon Murdoch $(1993,90)$, celui qui adopte la langue du colonisateur « devient à la fois étranger et natif, le Même et l'Autre ». La langue-armure protège le père : les indigènes le respectent (cf. Djebar 2007, 71), les « Autres » reculent devant sa prononciation française impeccable (cf. Djebar 2007, 44). Mais ni les uns, ni les autres ne le considèrent sans doute comme l'un des leurs. "C'est à travers la langue que tout individu intègre les distinctions et les valeurs à partir desquelles il va accéder à la place, au statut qui lui sont assignés pour "inter-agir" avec les autres » (Bensekhar Bennabi 1995, 117). Dans le cas du père de la narratrice, cette interaction est remise en question. Prononçant parfaitement les sons français, il bégaie lorsqu'il se met à parler sa langue maternelle. C'est en français qu'il explique à sa fille de quatre ou cinq ans qu'elle ne peut jamais évoquer devant sa mère son petit frère décédé : «Me parler en arabe, cet arabe qui [1]e fait bégayer quand l'émotion l'étreint, aurait été inefficace... », dit la narratrice (Djebar 2007, 74). La langue du colonisateur devient la langue de la complicité du père et de la fille. Le français se détache du contexte colonial et devient leur langue à eux.

Voulant être comme son père, la narratrice adopte le français qui devient aussi son armure à elle, son voile. Adolescente, elle transgresse les règles imposées par le père et se met à écrire des lettres à Tarik, garçon arabe qu'elle projette de rencontrer : 
Je nous voyais marcher côte à côte et deviser en français, bien sûr. Converser de la première fois en arabe m'aurait paru succomber à une familiarité hâtive, et pas seulement parce que, dans ma langue maternelle, l'arabe dialectal, le tutoiement est le plus souvent de règle. Le français, si neutre, me tiendrait lieu, en quelque sorte, de voile. (Djebar 2007, 264)

Le français remplace le voile réel quand la jeune fille prend goût aux promenades solitaires en ville :

Je me souviens de ma première année à déambuler sans fin dans Alger, et de cette ivresse qui me saisissait alors : avancer les yeux baissés, rougir d'être prise pour une Européenne, car rares encore étaient les adolescentes qui, comme moi, se plaisaient à marcher pour marcher ... Surtout ne pas parler au-dehors sa langue de cœur, je veux dire sa langue maternelle [...] ; surtout ne pas user de cette langue d'intimité avec un homme arabe : aussitôt, il vous scruterait, son respect naturel envers une Européenne de tout âge se changerait en hostilité vis-à-vis d'une jeune fille de sa communauté [...]. Pas question de vous dévoiler devant eux, ni de révéler votre identité : alors que vous étiez de fait, dévoilée! Mais aussi masquée par la langue étrangère ! (Djebar 2007, 305)

La langue française sert de masque et s’oppose à la « langue de cœur », langue maternelle. Cette opposition binaire est pourtant trop simpliste. La narratrice ne parle-t-elle pas français avec son père ? Il semble qu'il y ait plus d'un français dont la narratrice se sert : le français de complicité qu'elle parle avec son père, le français-masque qu'elle utilise pour ne pas être harcelée dans la rue, le français de distance qu'elle adopte lors des conversation avec Tarik :

Nous parlions, je me souviens, en français : subsistait en moi une certaine résistance, ou une forme de pudeur, le français me devenait une langue neutre, alors qu'avec lui, mon premier amoureux, les mots d'amour dans ma langue maternelle - qui était aussi la sienne - auraient jailli maladroitement. L'usage d'arabe pour exprimer l'amour m'aurait sans doute semblé, je ne savais pourquoi, indécent ... (Djebar 2007, 321)

La langue maternelle devient, à son tour, langue d'intimité et de sensualité. Ali, le Saharien, avec qui Fatima va se promener après le spectacle scolaire, lui demande un baiser en français. La narratrice refuse et s'enfuit. Des années après, elle se demande si sa réaction n'a pas été provoquée par la langue employée par le garçon : « [et s'il] m’avait, lui, demandé un baiser dans notre langue, peut-être aurais-je cédé, car la musique de son dialecte du Sud aurait sans doute fait naître en moi le désir d'effleurer ses lèvres » (Djebar 2007, 264). L'arabe est une langue à multiples accents mélodiques que la narratrice admire. C'est aussi la langue de la poésie préislamique, arabe classique qu'elle ne peut pas apprendre à l'école et que Tarik étudie. Dans ses lettres, il lui copie des poèmes qu'elle attend impatiemment, arrivant à identifier le garçon à la langue : «Tarik n’utilisait jamais avec moi les vocables chatoyants des poètes d'autrefois, qu'il aurait pu me réciter d'une 
voix chuchotante à l'oreille : alors je me serais blottie plus ardemment dans ses bras ... » (Djebar 2007, 322).

La langue est « garante d'unité » (Bensekhar Bennabi 1995, 118), mais chez Assia Djebar « [1]a langue n'est plus une ; elle se décline, plus que jamais, en divers et s'invente en imprévisibles hybridités » (Ali-Benali et Simasotchi-Bronès 2009, 56). Cela ressemble à la structure du rhizome. " Pourquoi l'entre-deux-langue ? Pourquoi pas l'entre-langues au pluriel ? ", dit l'écrivaine, elle-même, dans Ces voix qui m'assiègent (Djebar 1999, 30).

Ainsi le français ne s'oppose-t-il pas à l'arabe, mais devient son deuxième visage. Dans la quatrième lettre de Tarik, la narratrice retrouve un poème préislamique, et sa traduction, qu'elle relit la nuit :

[...] j'ai fini par rêver que les deux versions, dans ma langue maternelle et dans celle de Nerval, oui, ces deux formes sonores, à en palper la trace sous le drap, puis à réentendre le rythme de l'arabe et du français, comme accouplés tout contre moi, devenaient, dans mon sommeil strié d'absence, mais empreint de volupté, comme les deux visages d'une même poésie enveloppant mon corps de dormeuse, en lieu et place des draps [...]. (Djebar 2007, 291)

Ces draps qui enveloppent la dormeuse font penser au linceul ; les rhizomes linguistiques de la réalité coloniale peuvent-ils étouffer le moi qui se cherche parmi eux?

\section{La culture ou « un pont fragile »}

La narratrice appelle le français « langue de Nerval » et le rattache ainsi à la culture qu'il représente. Tout au début du livre, elle raconte qu'à l'âge de cinq ou six ans elle est revenue de l'école avec son premier livre français, Sans famille d'Hector Malot, qu'elle s'est mise à lire « comme on boit ou comme on se noie » (Djebar 2007, 19). Pour Djebar, l'éducation française reste une découverte fascinante (Connell 2013, 305). La culture de l'Autre l'émerveille.

L'histoire racontée par Malot étant triste, la petite Fatima se met à sangloter. Inquiète, la mère accourt et apprend que sa fille « lit ». Ne parlant pas français, elle ne comprend pas. Une frontière se dresse entre sa petite fille qui maîtrise la langue de l'Autre et elle-même. Pourtant, comme l'affirme la narratrice, la mère réussit à concevoir « un pont fragile entre la sensibilité qu'excitaient en moi ces histoires occidentales et la beauté secrète, sans égale, pour elle, des vers andalous qu'elle fredonnait, tout émue » (Djebar 2007, 21).

L'adhésion, avec ce premier livre, au monde de la culture française ne signifie pas l'exclusion de sa propre culture. Les vers andalous fredonnés par la mère 
deviennent un point de référence important. Contrairement à la culture française qui, dans Nulle part dans la maison de mon père, est avant tout celle du XIX ${ }^{\mathrm{e}}$ siècle, la culture algérienne, représentée par les chants andalous et poèmes préislamiques, semble très ancienne. Djebar montre que l’Orient, dominé à présent par l’Occident, l’a longtemps influencé :

Les Mo'allaquats, ces odes célèbres, se déployaient, elles, avec un lyrisme que j'imaginais pur ou sensuel et, me disais-je, avec un romantisme qui jaillissait en moi, presque malgré moi, qui parlait d'amour, d'un amour absolu : cette inspiration qui avait fleuri ensuite en Andalousie avait influencé la poésie des troubadours et l'« amour courtois » du Moyen Âge occidental. (Djebar 2007, 286)

Djebar prouve que les deux cultures, apparemment tellement différentes, ont des choses en commun.

Cette union entre les deux cultures apparaît aussi quand, à l'âge de 10 ans, la narratrice découvre les vers de Baudelaire. Le poème récité par l'enseignante, Mme Blasi, évoque la lecture du Coran : « elle qui m’a donné [...] à boire le tout premier vers français, prononcé comme j'étais auparavant habituée à recevoir seulement les versets du Coran : avec une lenteur quasi majestueuse, une gravité à peine marquée, une fluidité tranquille, presque fervente dans sa chute » (Djebar 2007, 102). L'enseignante récitant L'invitation au voyage, les deux cultures s'unissent, pourtant, dans le contexte de la mort.

Les deux héritages, celui du colonisateur et celui du colonisé, s'entremêlent. Certes, la narratrice lit beaucoup en français. Mais elle n'oublie pas l'héritage algérien, qui reste celui de son cœur. « Je suis, sans nul doute, une femme d'éducation française [...] et de sensibilité algérienne, ou arabo-berbère, ou même musulmane lorsque l'islam est vécu comme une culture », dit Djebar $(1999,26)$. Il est généralement admis que l'homme colonial (et postcolonial) est « traversé par les traces de deux imaginaires, de deux cultures, vivant une sorte d'entre-deux » (Cheniki 2012, 92). Chez Djebar, ces cultures et imaginaires se côtoient et laissent échapper des tiges imprévisibles à l'instar d'un rhizome.

\section{La tradition ou « le mot "honneur" [qui] arrive au galop »}

Stuart Hall $(2003,2)$ propose de ne pas parler de l'identité, mais plutôt de l'identification, qui se fonde sur la reconnaissance des origines ou des caractéristiques communes d'un groupe. Le « sentiment d'identité culturelle provient de l'appartenance à un même groupe dont la définition et la cohésion reposent sur un 
système, commun et relativement cohérent, de valeurs et d'institutions » (Memmi 1995, 17). Mais quel groupe choisir dans le contexte colonial ? L'Orient musulman est différent de l'Occident laïcisé. Les traditions, mœurs et coutumes des Algériens diffèrent de celles des Français. C’est aussi dans ce conflit que se dresse l’identité du colonisé.

Par l'éducation et la profession de son père, la petite Fatima accède au monde des Autres. Les jeunes filles de sa famille lui envient ses jupes de « petite Française » et ses " poupées comme chez les Français ». La petite est pourtant gênée par sa jupe écossaise trop courte lorsqu'elle s'assoit en tailleur et l'échangerait volontiers contre le « pantalon bouffant à la turque, tout de satin fleuri » des envieuses (Djebar 2007, 17). Le corps est « le lieu d'ancrage » (cf. Fischer 2017, 93), mais cet ancrage risque de se perdre entre les deux traditions opposées. Traitée comme une Française par les filles de sa famille, Fatima se rend compte qu'elle n'appartient pas à leur monde. Elle se sent « la fille de [s]on père » et se demande si c'est « [u]ne forme d'exclusion - ou de grâce » (Djebar 2007, 18).

C'est sans doute une forme de grâce car, envoyée par son père à l'école française, la narratrice échappe à la claustration obligatoire des jeunes filles musulmanes : " Née en Algérie coloniale, fillette arabe allant à l'école française l'école primaire du village - seule "musulmane" disait-on alors pour définir mon étrangeté, et par là-même ma famille ainsi que mon statut de “colonisée”, j’ai eu pourtant, presque miraculeusement, bien que fille, accès à l'école des Autres ... " (Djebar 2010b, 17). L'école française lui donne la liberté, le pouvoir et la mobilité (cf. Connell 2013, 302), mais la situe aussi entre les deux traditions, montre qu'elle diffère à la fois de ses compatriotes et des Françaises, l'exclut.

La mère de la narratrice, représentant généralement la tradition algérienne, change aussi sous l'influence de son mari, ou plutôt, des coutumes du colonisateur qu'il adopte. Les premières pages du livre mettent en scène la mère, " enveloppée de pied en cap dans un voile de satin blanc », qui traverse Césarée accompagnée de sa petite fille, les femmes ne pouvant pas y marcher seules (Djebar 2007, 14). Ce voile sera bientôt rangé au fond de l'armoire. Une fois arrivée à Alger, la mère se métamorphose " en une femme d'apparence européenne » (Djebar 2007, 302) : elle ne porte plus le voile, se rend seule au marché, accompagne sa petite dernière à l'école. Cela montre bien que le partage entre la mère et le père, représentant l'une, la culture algérienne, l'autre, la culture européenne, est trop simpliste. Tous deux incarnent les deux traditions dans les proportions variables, ce qui ressemble aussi à une structure rhizomorphe imprévisible.

Or, ce père qui a profité de l'éducation française, qui a voulu que sa fille porte des jupes françaises et l'a envoyée à l'école ne peut pas oublier son rôle du « père-gardien », " père-censeur », " père intransigeant » (Djebar 2007, 178). Il devient parfois un inconnu, un autre que sa fille ne reconnaît pas. La première 
situation où le père montre son deuxième visage a lieu quand sa fille de cinq ans apprend à faire du vélo. La voyant accompagnée d'un voisin français et exposant ses jambes nues, le père entre dans une colère noire. Il ne représente plus les traditions européennes, mais les mœurs islamiques les plus sévères : « Je ne veux pas, non, je ne veux pas - répète-t-il très haut à ma mère, accourue et silencieuse -, je ne veux pas que ma fille montre ses jambes en montant à bicyclette ! » (Djebar 2007, 49).

Les jambes nues deviennent une sorte d'obsession du père, qui interdit à sa fille adolescente de porter un short en dehors de la salle de gymnastique de son école. Cette fois-ci, pourtant, la narratrice transgresse l'interdit paternel et se rend en secret aux tournois sportifs dans d'autres établissements. Cependant, elle a toujours des remords, qui s'amplifient encore lorsqu'elle se lance dans une correspondance amoureuse avec Tarik, dont la première lettre a été déchirée par le père, fâché, défendant à sa fille toute forme de contact avec ce garçon si hardi.

La narratrice ose agir contre la volonté du père, mais n'arrive pas à se débarrasser de son sentiment de culpabilité. Le père, et avant tout la tradition patriarcale islamique qu'il incarne, devient une sorte de surmoi (Medeiros 2012, 281). Quand, à l'école, une amie française raconte à la narratrice ses premières expérience amoureuses, celle-ci est indignée comme son père qui voit sa fillette monter à vélo :

Je n'en parlerai ni à ma mère, ni surtout à mon père ! Dans ce cas, chez nous, le mot « honneur » arrive au galop ; d'ailleurs, je me sens - et avec quelle fermeté ! - intouchable. Je rameute en moi cet « honneur »; je le pense en langue arabe [...]. Moi, je demeure inébranlable dans l'attachement à nos valeurs. J'irais même jusqu'à plaindre cette amie : un tel laisser-aller de son corps, dans les bras d'un autre, me paraît presque bestial ... Et la pureté, mademoiselle? (Djebar 2007, 177)

La narratrice prend elle-même le rôle d'un censeur. Son attitude envers les mœurs européennes devient ambiguë. D’une part, il lui arrive de montrer que « les Françaises ignorent toute pudeur » (Djebar 2007, 176). D’autre part, à l'internat, avec ses camarades musulmanes, elles font « le bilan de [leurs] frustrations, en comparant [leur] vie à celle des adolescentes françaises » (Djebar 2007, 272).

Pour Albert Memmi (1973, 120), le colonisé vit déchiré entre l'amour du colonisateur et son refus. Il se place entre les deux traditions, ayant du mal à définir à quel groupe s’identifier. Les deux traditions, mœurs, coutumes s'enchevêtrent à l'instar d'un rhizome, mais ici, contrairement à la langue ou à la culture, la coexistence devient dramatique. Dominique D. Fischer $(2017,99)$ parle de « la double altérité dans laquelle la narratrice se situe vis-à-vis de son héritage culturel et vis-à-vis des “Autres” ». Sa tentative de suicide est un essai de se libérer, d'en finir avec la tradition patriarcale islamique difficile à accepter face à la tradition 
française, beaucoup plus libérale. Djebar montre par cela la fragilité de l'identité coloniale, l'impossibilité de réconcilier l'Orient et l'Occident.

\section{En guise de conclusion}

« C'est un rhizome, un terrier », disaient Deleuze et Guattari (1975, 7), en décrivant l'œuvre de Kafka. Il semble que cette phrase s'applique non seulement à l'écriture djebarienne (cf. Sokołowicz 2017a, 169-183), mais aussi à l'identité postcoloniale (cf. Fulford 2002, 27) qu'elle décrit.

Nulle part dans la maison de mon père met en scène une jeune fille algérienne qui va à l'école dans l'Algérie coloniale, une jeune fille influencée par deux langues, deux héritages culturels et deux traditions qui s'enchevêtrent à l'instar d'un rhizome, qui se complètent et, plus souvent, s'opposent : « Il y a rupture dans le rhizome chaque fois que des lignes segmentaires explosent dans une ligne de fuite, mais la ligne de fuite fait partie du rhizome. Ces lignes ne cessent de se renvoyer les unes aux autres » (Deleuze et Guattari 1979, 28).

Le rhizome continue à bouger, n'est jamais immobile (cf. Fulford 2002, 28). Force est de constater que l'image revenant dans Nulle part dans la maison de mon père est celle de la narratrice en train de marcher : au début auprès de sa mère, en tant que « son page ou même son garant » (Djebar 2007, 15), puis avec son père qui l'accompagne à l'école, avec une amie qui l'encourage à découvrir la ville, en compagnie du beau Saharien, puis de Tarik. Elle déambule aussi seule dans les rues d'Alger. C'est en marchant, en mouvement, qu'elle semble retrouver une paix relative. La marche, et parfois l'errance, devient la métaphore de la recherche de soi. "Tatouée, tu marches sans savoir où, l'horizon droit devant », se dit la narratrice à la fin du roman (Djebar 2007, 398). Perdu dans la réalité, tout à fait rhizomorphe, l'être colonial ne voit qu'une certitude : la mort.

C'est pourquoi, sans doute, les errances en ville se changent parfois en courses folles. La petite fillette se met à courir quand elle apprend la mort de sa grand-mère : « je ne perçois plus rien, toute douleur est à la fois abolie et sans fin, les main de ma grand-mère, la nuit, me caressant contre le froid, ces mains, où les retrouver, sous quel ciel, courir jusqu'à la mer, jusqu'au port, jusqu'au bout ! » (Djebar 2007, 24). Cette course pleine de douleur faisant penser à la course vers la mort revient à la fin du roman. Après la dispute avec Tarik, la narratrice se met à courir une fois encore : "M'en aller au plus loin, courir au plus vite, me précipiter, me projeter là-bas, éperdue, au point exact où se noie l'horizon ! Ne m’arrêter que là où la mer m’attend ... m’attend ... » (Djebar 2007, 356). La mer, homophone de la « mère », désigne l'enfance, les caresses de la grand-mère, le sentiment de 
l'appartenance perdu avec l'âge. « Devenir un point dans l'espace ! Courir ! Il me semble à présent que je cours encore ... », s'exclame la narratrice (Djebar 2007, 356), même si l'arrivée du tramway a mis fin à sa course.

La tentative de suicide montre que la recherche de soi dans la société coloniale peut échouer. La narratrice n'arrive pas à se retrouver entre Orient et Occident. C'est pourquoi elle désire la mort. Dans la réalité postcoloniale, déjà adulte, elle continue à chercher sa place et elle-même : " Je suis sans lieu là-bas depuis ce jour d'octobre [...]. Depuis cette aube de 1953, [...] je cherche, moi, inlassable, où se trouve la petite, l'obscure maison de mon père » (Djebar 2007, 386).

Les écrivains postcoloniaux écrivent « en dehors de leurs pays ", « en dehors de leur langue » (cf. Ponzanesi 2004, 20), dans une sorte de non-lieu où ils cherchent, au moins, « la petite, l'obscure maison ». Selon Stuart Hall (2003, 4), construire son identité ne veut pas dire chercher ses racines, mais les accepter. Chez Assia Djebar, les racines se font rhizomes, qu'on retrouve dans son œuvre, entre autres, sous les noms de " mélange ", " magma » ou " architecture arachnéenne » (Djebar 2007, 406). Entre Orient et Occident, colonisé et colonisateur, parmi plusieurs langues, plusieurs héritages culturels et traditions, pousse un moi (post)colonial fracturé, tubéreux, enchevêtré, tel un rhizome d'où il émerge.

\section{Bibliographie}

Ali-Benali, Zineb, et Simasotchi-Bronès, Françoise. « Comme une étrange annonce. D’une certaine pratique de la langue à la théorisation du postcolonial ». Littérature 154.2 (2009) : 53-66.

Bensekhar Bennabi, Malika. « Enjeux linguistiques et identitaires en Algérie ». Y a-t-il un dialogue interculturel dans les pays francophones? Actes du Colloque International de l'AEFECO Vienne, 19-23 avril 1995. Tome I. Vienne : Cahiers Francophones d'Europe CentreOrientale, 1995. 117-121.

Cheniki, Ahmed. «Algérie-France. Expériences culturelles et aventures ambiguës ». Hommes et migrations. 1298 (2012) : 82-94.

Connell, Lisa. « Movement, Education, and Empowerment in Assia Djebar's L'Amour, la fantasia and Nulle part dans la maison de mon père ». Contemporary Women's Writing 7.3 (2013) : 291-308.

Deleuze, Gilles, et Guattari, Félix. Kafka. Pour une littérature mineure. Paris : Les Éditions de Minuit, 1975.

Deleuze, Gilles, et Guattari, Félix. Rhizome. Introduction. Paris : Les Éditions de Minuit, 1979.

Djebar, Assia. Ces voix qui m'assiègent. Paris : Albin Michel, 1999.

Djebar, Assia. Nulle part dans la maison de mon père. Paris : Fayard, 2007.

Djebar, Assia. «Discours d'entrée à l'Académie Française ». Assia Djebar. Littérature et transmission. Wolfgang Asholt, Mireille Calle-Gruber et Dominique Combe (dir.). Paris : Presses Sorbonne Nouvelle, 2010a. 403-420. 
Djebar, Assia. «Étrangère ... de l'intérieur ». Assia Djebar. Littérature et transmission. Wolfgang Asholt, Mireille Calle-Gruber et Dominique Combe (dir.). Paris : Presses Sorbonne Nouvelle, 2010b. 17-21.

Djebar, Assia. L'Amour, la fantasia. Paris : Albin Michel, 2014 [1985].

Fischer, Dominique D. « Nulle part dans la maison de mon père. Une éthique du dévoi(l)e/ment ». Assia Djebar et la transgression des limites linguistiques, littéraires, littéraires et culturelles. Wolfgang Asholt et Lise Gauvin (dir.). Paris : Classiques Garnier, 2017. 89-103.

Fulford, Sarah. Gendered Spaces in Contemporary Irish Poetry. Berne : Peter Lang, 2002.

Green, Mary Jean. " Dismantling the Colonizing Text: Anne Hébert's Kamouraska and Assia Djebar's L'Amour, la fantasia ». The French Review 66.6 (1993) : 959-966.

Hall, Stuart. "Introduction: Who Needs "Identity”? ». Questions of Cultural Identity. Stuart Hall and Paul Du Gay (dir.). London : Sage Publications, 2003. 1-17.

Medeiros, Ana de. «Writing as wounding and healing in Djebar's Nulle part dans la maison de mon père ». International Journal of Francophone Studies 2.15 (2012) : 277-296.

Memmi, Albert. Portrait du colonisé. Paris : Payot, 1973.

Memmi, Albert. «Qu'est-ce que l'identité culturelle ? ». Y a-t-il un dialogue interculturel dans les pays francophones? Actes du Colloque International de l'AEFECO Vienne, 19-23 avril 1995. Tome I. Vienne : Cahiers Francophones d'Europe Centre-Orientale, 1995. 15-31.

Mortimer, Mildred. «Writing the Personal. The Evolution of Assia Djebar's Autobiographical Project, from L'Amour, la Fantasia to Nulle Part dans la Maison de mon Père ». Journal of Women's History 2.25 (2013) : 111-129.

Murdoch, Adlai (H.). « Rewriting Writing: Identity, Exile and Renewal in Assia Djebar's L'Amour, la fantasia ». Yale French Studies 83.2 (1993) : 71-92.

Ponzanesi, Sandra. Paradoxes of Postcolonial Culture. Contemporary Women Writers of the Indian and Afro-Italian Diaspora. New York: State University of New York Press, 2004.

Provitola, Blase Anna. « Feminism in the Father Book: Complicating the Emancipation Narrative in Assia Djebar's Nowhere in My Father's House ». The Romantic Review 1-4.106 (2015) : 71-92.

Selao, Ching, «(Im)possible autobiographie : vers une lecture derridienne de L’Amour, la fantasia d’Assia Djebar ». Études françaises 40.3 (2004) : 129-150.

Sokołowicz, Małgorzata. « “L’héritage qui m’encombre...”. L'esthétique rhizomorphe dans L’Amour, la fantasia ». Wolfgang Asholt et Lise Gauvin (dir.). Paris : Classiques Garnier, 2017a. 169-183.

Sokołowicz, Małgorzata. "Se libérer de l'emprise de l'Histoire. L'idéologie postcoloniale dans L'Amour, la fantasia d'Assia Djebar ». Texte et idéologie en contexte postcolonial. RichardLaurent Omgba (dir.). Yaoundé : Éditions CLE, 2017b. 47-66.

Tageldin, Shaden. « Which Qalam for Algeria?: Colonialism, Liberation, and Language in Djebar's L'Amour, la fantasia and Mustaghānimī’s Dhākirat Al-Jasad ». Comparative Literature Studies 46.3 (2009) : 467-497. 
Małgorzata Sokołowicz, associate professor at the French Studies Department of the University of Warsaw, is the author of the books La Catégorie du héros romantique dans la poésie française et polonaise au XIXe siècle (2014) and Orientalisme, colonialisme, interculturalité. L'œuvre d'Aline Réveillaud de Lens (2020), as well as numerous papers analysing relations between literature and art, orientalism, and the issue of identity. 